\title{
Commentary
}

\section{Ethical issues in the provision of assisted reproduction}

\author{
Harshalal R Seneviratne ${ }^{1}$ \\ Sri Lanka Journal of Obstetrics and Gynaecology 2011; 33: 77-83
}

\begin{abstract}
While the global and the Sri Lankan populations are still increasing those who require the whole range of infertility treatment is also on the rise. Ethical considerations in provision of infertility care have been a cause for concern from ancient times as to have a child, "even at any cost", is a basic human biological need. With the availability of the higher levels of technology by way of Assisted Reproductive Technology (ART) for treatment of childlessness the opportunities to manipulate biological material, modify protocols, and for commercialization are greater. The social, legal, religious and other issues within the context of ethically correct practices are presented for consideration by the care providers and policy makers. While the first steps in monitoring the provision of ART have been taken by the Sri Lanka Medical Council by publishing the "Code of Practice" the foundations for establishing a regulatory authority also have been initiated. Such an Authority would need to have the correct balance between ethically correct practices and justifiable restrictions.
\end{abstract}

\section{Introduction}

The annual growth rate of the world population has decreased from $2.2 \%$ in 1962 to a steady $1.14 \%$ during the past few years ${ }^{1}$. Estimates indicate that 1 in 6 to 1 in 7 couples in the United Kingdom (UK) need assistance to conceive and this need is expected to rise further ${ }^{2}$. While approximately $84 \%$ of couples conceive within 12 months and $92 \%$ in 24 months of trying for a pregnancy those needing advanced Assisted Reproductive Technologies (ART) pose a noteworthy public health problem ${ }^{2}$. Infertility is a problem which cuts across social, cultural and religious sensitivities. With the spread of ART to Sri Lanka it is appropriate to consider the relevant ethical

\footnotetext{
${ }^{1}$ Department of Obstetrics and Gynaecology, Faculty of Medicine, University of Colombo, Sri Lanka. Correspondence: Harshalal Seneviratne E-mail:prof_sene@yahoo.co.uk
}

issues. This presentation aims to encourage the individual practitioners and teams of ART providers to focus on these issues. In customizing the provision of ART to the needs of the individual couple religious beliefs and social practices of the relevant community have to be considered. The active participation of the public to establish ethical norms for the provision of ART is mandatory.

Following the birth on 7th July 1978 of the first baby conceived by in-vitro fertilization (IVF) the significance of the potential ethical, legal, social, and cultural impact remained unappreciated ${ }^{3}$ until more ART babies were born in subsequent years. A committee headed by Dame Mary Warnock was appointed to study the subject in depth and to make recommendations for the future provision of ART services ${ }^{4}$. The technological and the social norms have changed globally since then although the principles stated in the Warnock Report are still applicable.

ART is unique amongst treatment methods for infertility since the ova are extracted, maintained and fertilized outside the human body. Embryos obtained by in-vitro insemination and fertilization of oocytes are cultured in vitro to the stages of morulae or blastocysts then transferred into the uterine cavity. The spermatozoa, ova and early embryos would therefore be exposed to manipulation. Although the original intention of this treatment was to provide for reproduction today ART has created opportunities for ever increasing unintentional or deliberate genetic and molecular biological interventions. These possibilities create wide variations in the provision of ART in different countries and have affected access to ART and / or the individual components of this treatment ${ }^{5}$. The social, cultural and religious impact during clinical practice of ART has to be considered as they form the basis for establishing ethical and legal norms.

\section{Religion and ART}

Religious views on ART have been diverse and continue to generate much discussion. Religions practiced in Sri Lanka favour helping the infertile couple to achieve parenthood. The main religious issues relate to the manner in which the gametes and embryos are obtained, processed and disposed. 
Directions from the Christian and Catholic Church emphasise the necessity for conjugal love for reproduction ${ }^{6,7}$. It raises serious practical issues for the ART provider and the couple seeking treatment since suitable seminal samples can be obtained at present only by non-coital means. The necessity to retrieve ova out of the body is also a contentious issue. Technology directed towards developing safe and effective sheaths which sustain the quality of spermatozoa may be acceptable to the followers of the gospel. Educating the public including the clergy on the nature and processes of ART will no doubt help to develop solutions to this issue.

Islamic religion supports reproduction ${ }^{8}$. Males are permitted to have several female spouses but the involvement of a third party for reproduction is barred. Gamete and embryo donation as well as surrogacy are unacceptable ${ }^{9}$ even though the third person participating may be one of the other wives of the same man. This restriction eliminates the use of certain procedures in ART which may be the only choice to achieve parenthood for some couples.

Buddhist philosophy favours helping the infertile couple and ARTs are considered to be valid treatment options ${ }^{10}$. As Buddhism favours preservation of life it would support the storage of embryos which helps to prevent their destruction. Each extension of the ART technology should be individually matched against Buddhist principles. Buddhist clergy and lay personalities have been slow to discuss such issues. The late Dr. Anand Kumar a leading scientist on Reproductive Biology similarly states "Hinduism has no serious conflict with the provision of ART but is an issue that has never been debated adequately"11.

The work of the ART providers and the counsellors would be very complex if no direction is provided by the different religions on the many applications of ART. Participation by religious representatives as stakeholders in developing future guidelines is urgently needed. The confusion prevailing in the minds of those seeking treatment could be minimised if the different religious establishments appreciate the need, the processes and the ever changing technology for provision of ART. Guilt and regret may occur in couples following such treatment as it may be perceived as being contrary to their individual religious teachings and beliefs.

\section{The status of the embryo}

The human embryo is considered by some as representing a stage of "life" and should therefore be protected from manipulation for research. Central to this issue is the biological end point of embryo life and the beginning of foetal life. The Human Foetal and Embryo Authority of UK defined, and in 1994 the National Institutes of Health (NIH) Human Embryo Research Panel proposed a limit of 14 days after fertilization for the use of embryos for research ${ }^{2,12}$. The primitive streak is identified at this stage and uniovular twinning does not occur beyond day 14 after fertilization ${ }^{12,13}$. Coincidentally an analysis by Damien Keown in "Buddhism and Bioethics" on the application of Buddhist philosophy to the beginning of life, highlights that the unborn being develops "consciousness" within the first month of its existence ${ }^{10}$. Clearly research involving human embryos need very special considerations beyond those accepted as ethical guidelines for conducting general human research ${ }^{14}$. Although presently ART related research is conducted infrequently in Sri Lanka an increase can be anticipated in the future. The ethics committees evaluating such requests need to ensure that their decisions are correctly balanced between ethically correct practices and justifiable restrictions.

\section{Stem cells and cloning}

In the future cloning and embryonic stem cell (ESC) technologies may be introduced to Sri Lanka. They are ART related procedures which are in the fore front of the ethical debate ${ }^{15}$. Globally reproductive cloning is considered to be a morally contentious area. Stem cells are however multi-potential cells with the possibility of replacing virtually any tissue system or organ in the human body ${ }^{16}$. While the therapeutic application of stem cells give hope to those who suffer from a range of diseases the uncertainties involving the origins of the stem cell lines and its potential for uncontrolled complications highlight the ethical dilemma of their use at present. The technologies for use of ESC have advanced from the laboratory origins in the $1990 \mathrm{~s}^{17}$ to the clinical applications envisaged today $^{18}$. This concern can be reduced by avoiding cloning or by the use of embryonic stem cells. Expanding the alternative facilities for adult and cord blood stem cell technology would be desirable for this purpose $^{19}$. Alternative sources such as amniotic fluid seem to offer some hope for a more ethically acceptable stem cell facility ${ }^{20}$. Cord blood stem cell services need dedicated technological inputs, accurate record keeping and a robust authority to oversee its activities. Governments and the scientific community have so far been lethargic in providing direction for establishing such a facility.

\section{Follicular enhancement and multiple embryos}

In natural ovarian cycles only 4 to 6 follicles are recruited and one or two mature for ovulation ${ }^{21}$. During ART multiple follicular recruitment and maturation 
is done so that many ova can be harvested. Excess embryos may therefore result per ART cycle. Unused embryos were allowed to perish prior to the availability of embryo freezing techniques. While freezing of excess embryos solves the problem of excess embryos initially it also places the couple in an ethical dilemma when their family is complete and a decision has to be eventually made regards the fate of remaining embryos. The alternative options are to donate the spare embryos to other infertile couples, donate for research or as in the past to allow them to perish. All these measures are fraught with ethical issues ${ }^{22}$. Couples who do not wish their offspring to be parented by others find embryo donation unacceptable. Many couples are also uneasy to use embryos for therapeutic processing of stem cells or for embryo research. Although such numbers are small permitting the unused frozen embryos to perish under laboratory conditions may be the only choice for some couples. This recreates the ethical and moral dilemma for the ART team and the infertile couple.

A recently introduced concept is the use of minimal stimulation of follicular development ${ }^{23}$. It uses the natural phenomenon of a limited cohort of follicular recruitment while enhancing the maturation of the selected follicles. The number of retrieved ova would therefore be limited and those available for fertilization would be the naturally selected best in the cohort. The problem of excess embryos would therefore be limited to a manageable number.

\section{Status of the child, the gamete donors, and the recipient parent}

Many of the social, cultural, and ethical issues in ART relate to the relationship of the offspring to the parents. In natural reproduction the genetic, biological and legal parents would be those who provided the gametes. The ability to manipulate the ova and the spermatozoa creates many possible variations which need serious ethical considerations.

Previously severe male factor deficiency was treated by direct intra-vaginal insemination of donated semen or cohabitation with the donor. These practices present many health and ethical concerns. They have been replaced by the safer intra-uterine or intra-vaginal insemination of sperms processed by separation of the seminal plasma. Donor sperm is now used only after excluding genital infections including HIV/AIDS, and karyotyping. Ensuring confidentiality is mandatory. Guidelines for this purpose have been established, and need adherence.

Ovum donation was possible only after the availability of ART. Ova obtained from the donor are inseminated with the spermatozoa provided by the male partner or a donor. The resulting embryo is placed within the prepared uterus of the female partner of the recipient couple. The latter is considered as the biological and legal mother of the baby to be born although the donor has supplied the female gametes. Ovum donation is considered to be devoid of the sexual connotations associated with the use of donor sperm. The ethical issues arising from both donor male and female gametes are however very diverse. The relationship of the donor to each partner of the recipient couple needs to be considered so as to avoid the possibility of genetically related "incest". International and Sri Lankan guidelines which ensure ethically correct practices are now available ${ }^{24,25}$.

Gamete donation has an effect on the genetic composition of a population. A marital relationship between offspring of the same donated gamete origin is always possible. To minimize this effect the HFEA of UK has placed a ten pregnancy limit on the use of gametes of each donor ${ }^{24}$. The Guidelines of the SLMC have placed this limit at five pregnancies ${ }^{25}$. Although many factors including migration will influence this issue it is possible that pre-marital testing for biological compatibility of a couple would be advisable and could be a requirement in the future. Linked to this issue would be the nature and extent of information on their genetic origins that is divulged to the children who are born from donor procedures. Over the past few years the legislature for this purpose has been relaxed in $\mathrm{UK}^{24}$ and in many other countries. The elimination of anonymity of the donors has resulted in a marked reduction in the availability of donors which in turn has enhanced the practice of "ART tourism" to the developing countries and Eastern Europe. It has enhanced the commercialisation of ART. Such practices are ethically contentious and logistically unmanageable.

Egg sharing is an extension of ovum donation. A woman whose only option for pregnancy is ART (eg. extensively damaged fallopian tubes etc.) but is unable to afford the cost of the treatment offers to share some of her eggs developed by stimulated follicular development in exchange for sponsorship of the cost of treatment by a recipient woman who has poor follicular development. A system of ovum sharing which ensures the sharer's rights and avoids exploitation is in place. The manner of recruitment of the donor should be such that coercion, blackmail, bribery and commercialisation are avoided. Much debate has revolved around the ethics of remunerating the sharer the cost of the treatment. Pennings and Devroey ${ }^{26}$ comment following an analysis on possible reasons for eggs sharing that "subconscious coercion due to a lack of an alternative appears to play a 
substantial role in their decision". They conclude that "if infertility treatment is part of basic health care because it alleviates a fundamental need, the dilemma of egg sharing should be solved by subsidizing infertility treatment for people who cannot afford it". The Government of Sri Lanka is responsible for the provision of health care. Is it possible for the state to take the additional burden of providing at least one attempt of ART for those who need it? The chance of success at a low rate of approximately $35 \%$ would then have to be matched against an ethical dilemma created by the compulsion to share one's eggs. The potential recipients will also lose a ready source of ova for this treatment and would have to depend on voluntary donations.

\section{Ethics involving treatment procedures}

Although the routine treatment procedures in ART are now of common knowledge and regularly practiced new additions in technology occurs on a regular basis. It is necessary that these are evidence based or at least biologically acceptable. Accurate adherence to accepted practice norms will ensure good results and is an ethically expected requirement. Deviation from methodology to enhance results should be condemned. ART practices of mixing of gametes and embryos from different sources are totally unacceptable and unethical. It is very clear that pregnancies resulting from such a procedure would be of unknown genetic origin. The social implication of this practice is that such children born cannot be informed of their genetic parenthood. The temptation to resort to such a practice is great as it is deemed to improve the results at the ART centre.

Screening of the couple for HIV / AIDS is a standard practice in ART procedures because of the risk of transmission to staff, other ART participants, and between the couple seeking treatment. The ethical dilemma facing the ART care providers is whether to offer ART at all to such couples in view of the potential social issues which may arise. The limited life span of the parent who has HIV infection and the relationship between such parents are some of the issues which arise. More efficient medications now available to treat HIV infection has helped alleviate the problems to some extent. State support to establish a mechanism for constant health and social monitoring of children born to such parents is mandatory.

Surrogacy practiced from ancient times has been given a technological flavour by the availability of ART as gamete transfer is enabled without cohabitation. Surrogacy is therefore more ethically acceptable. The recruitment of the surrogate mother by coercion, compulsion or by payment of a fee though still ethically unacceptable is difficult to monitor or control. Part of such regulation would be to avoid genetic or social relationships of the surrogate mother to one or both partners of the index couple so as to avoid "therapeutic incest". Further the risk of bonding between the surrogate mother and the resulting off spring is ever present and separating them in a "humane manner" is an ideal which is difficult to achieve. Ever present is also the problem of who undertakes the responsibility of the care of the baby if it is found to be malformed. A regulatory authority is urgently needed to deal with ethico-legal issues involving surrogacy.

Simulating nature requires time and effort. The first successful IVF baby was born after approximately 200 failed attempts. That initial success rate of 1 in $200(0.5 \%)$ has now improved to $35 \%$ to $40 \%$ worldwide 3 . It still means that $60 \%$ to $65 \%$ of couples who have incurred high costs for this treatment would fail to achieve parenthood with one attempt. To the fertility care providers this low return of investment is an ethical dilemma during counselling, as the public expects a more reassuring result.

The current unimpressive success rates may affect client acceptance of the treatment. Those who require ART are in a very vulnerable state. They may therefore be exposed to unethical manipulation to accept ART as the most appropriate treatment when cheaper alternatives are still applicable. Informed choice for selecting ART after due consideration for fertility needs, affordability etc. is a right that should be exercised at all times. This is a major reason to establish a regulatory authority which could ensure that ART services conform to defined regulations and guidelines.

The task of such an authority extends also to ensuring meticulous adherence to technical protocols and provision of high quality equipment at ART centres.

The introduction of new protocols or modifications of old ones is an expected normal practice. Would the patients be adequately informed regarding these developments? Is it ethically correct to offer ART technologies when they have not been evaluated by clinical trials? ${ }^{27}$. Unlike many therapeutic interventions there are no mannequins and models for training in ART procedures in general and specifically to gain the dexterity needed for the very fine micro manipulations. Active participation in the treatment process is the only way in which future ART providers can be trained. This creates an ethical dilemma which could affect the continuation of the ART programmes. At best what could be ensured 
is that the procedures are always conducted under the direct supervision of experts in the field.

Access to all aspects of health care including those for fulfilling fertility intentions is a right that is stated in the United Nations declaration on Universal Human Rights ${ }^{28}$ of 1948 Article 16 -1. In spite of such a declaration being made 60 years ago in 1948 the access to high end services is available to only a restricted segment of the population. Access to and equity in the provision of ART also follows a similar pattern. Regrettably this availability is most often directly related to the financial resources of the client. Globally the availability of ART treatment varies very widely between countries. Some countries such as the United Kingdom have provided for a limited number of cycles of ART treatment at state expense. The subject needs to be discussed with the involvement of all stake holders.

There is no uniformity on the components of treatment procedures of ART that is permitted in different countries ${ }^{12}$. Practices such as gamete freezing, embryo storage, surrogacy, use of donor gametes etc. are examples of those steeped in controversy ${ }^{28}$. The social, religious and cultural attitudes and practices in each country form the basis for use of such practices. Restrictions create an ethical dilemma for the care providers and act as barriers to establishing international standards in the provision of ART. As these issues are country specific mechanism established locally to review newer technologies with a potential for their introduction into that country will do much to help in fulfilling the therapeutic requirements of infertile couples.

Conflict arises when the question "who owns the gametes or embryos?" has to be decided ${ }^{30}$. Multiple participants could claim the right to ownership of the stored gametes and embryos. These are the establishment where the material is stored and the couple who have provided the gametes. The problem arises when one or both members of the couple are unavailable after storage of the gametes or embryos. Who then has the ownership of the stored material? Posthumous use of gametes or embryos following chemotherapy for malignancy is one such example. It is clear that such situations should be anticipated and addressed during counselling prior to obtaining the material for storage.

Therapeutic interventions for treatment of infertility involve many steps which support, enhance or modify the natural process. Those scientific procedures which manipulate the biological steps involved in the creation of a "being" no doubt warrant very accurate and meticulous record keeping. This enables the determination of the epidemiology of infertility, assessment of adverse results of ART, counselling at all stages of treatment and enables the children born to gain knowledge of their genetic and biological origins. Lapses in documentation and record keeping can be considered as unethical and illegal.

Since the successful introduction of ART into clinical practice in 1978 the legal status of the human embryo has been a central issue in the relationship between the law and ethics ${ }^{24}$. Globally the constitutional status of the embryo varies country wise and can be expected to be determined by the religious preferences within the country. The opinion on status of the embryo comes into conflict between law and ethics when decisions have to be made on embryo research, designer embryos for therapeutic purposes, disposal of embryos etc. The ethical conflict is further enhanced by the ability of the state to enforce any or all of its decisions. It is therefore necessary that those institutions established to rule on such issues when they arise should consist of members who are technologically competent, are aware of the social and religious sensitivities of the country, knowledgeable of the law of the land, and have the maturity to deal with such situations. The "Code of Practice for Centres Providing ART" published by the Sri Lanka Medical Council ${ }^{25}$ is a step in the right direction which is expected to enhance the development of the legislature and establish an authority to overlook the practice of ART in the country.

\section{Conclusions}

Assisted reproduction has been one of the greatest advances in medicine achieved during the past five decades. It has however been associated with legal, religious, and ethical considerations in a complex manner. Clinical and laboratory care providers need to be conversant with these issues which goes beyond their technical expertise. Their responsibilities in this regard extend to ensuring advocacy amongst the policy makers, the clergy and their own peers as well as promoting the regulatory processes.

\footnotetext{
"There must be some barriers that are not to be crossed, some limits fixed beyond which people must not be allowed to go. Deciding on the barriers and limits is the responsibility of all of us based on our social, cultural and religious norms"
}

Dame Mary Warnock

(The Warnock Report, 1984) 


\section{References}

1. Rosenberg M. Current world population and world population growth since the year one. http:// geography.about.com/world population.html.

2. HFEA facts and figures (2011). www.hfea.gov.uk/en/ 406.html.

3. Edwards RG. Ethics and moral philosophy in the initiation of IVF, preimplantation diagnosis and stem cells. (Royal Society, London). Reproductive BioMedicine Online 2005; 10 (Supplement 1): 1-8. www.rbmonline.com/Article/1583 on web 31 January 2005.

4. Warnock M. Report of the Committee of Enquiry into Human Fertilization and Embryology. Department of Health and Social Security (by Command of Her Majesty) July 1984: 9314.

5. Murphy TF. Access and equity: international standards and assisted reproductive technologies. In: Ethics, Law and Moral Philosophy of Reproductive Biomedicine (Istanbul, Turkey 28 - 29 April 2006). Reproductive BioMedicine Online 2007; 14 (Supplement 1): 12-8. www.rbmonline.com/ Article/2418 on web 1November 2006.

6. Shea JB. The moral status of in vitro fertilization (IVF) biology and method. Catholic Insight 2006; 14: 48:37. www.catholicinsight.com/online/church/vatican/ article_475.shtml.

7. Schenker JG. Assisted reproductive practice: religious perspectives. Reproductive BioMedicine Online 2005; 10: 3109. www.rbmonline.com/article/1539 on web 13 January 2005.

8. Yeprem S. Current assisted reproduction treatment practices from an Islamic perspective. In: Ethics, Law and Moral Philosophy of Reproductive Biomedicine (Istanbul, Turkey 28 - 29 April 2006). Reproductive BioMedicine Online 2006; 14 (Supplement 1): 44-7. www.rbmonline.com/ Article/2445 on web 12 October 2006.

9. Serour GI, Dickens BM. Assisted reproduction developments in the Islamic world. International Journal of Gynaecology and Obstetrics 2001; 74: 187-93.

10. Keown D. At the beginning of life. In: Buddhism and Bioethics. Palgrave Publisher 1995, 2001; 65-73.

11. Anand Kumar TC. Ethical aspects of assisted reproduction - an Indian viewpoint. In: Ethics, Law and Moral Philosophy of Reproductive Biomedicine (Istanbul, Turkey 28 - 29 April 2006). Reproductive BioMedicine Online 2007; 14 (Supplement 1): 140-2. www.rbmonline.com/Article/2473 on web 15 November 2006.

12. Human embryo research. Committee on Paediatric Research and Committee on Bioethics. Policy statement (Reaffirmed on May 1, 2005), American Academy of Pediatrics. Pediatrics 2001; 108: 813-6.

13. Aksoy S. The beginning of human life and embryos: a philosophical and theological perspective. In: Ethics, Law and Moral Philosophy of Reproductive Biomedicine
(Istanbul, Turkey 28 - 29 April 2006). Reproductive BioMedicine Online 2007; 14 (Supplement 1): 86-92. www.rbmonline.com/Article/2444 on web 13 December 2006.

14. Pennigs G. The ethics of using embryos in research. In: Ethics, Law and Moral Philosophy of Reproductive Biomedicine (Istanbul, Turkey 28 - 29 April 2006). Reproductive BioMedicine Online 2007; 14 (Supplement 1): 92-7. www.rbmonline.com/Article/2411 on web 10 July 2006.

15. Steinbock B. The science, policy and ethics of stem cell research. In: Ethics, Law and Moral Philosophy of Reproductive Biomedicine (Istanbul, Turkey 28 - 29 April 2006). Reproductive BioMedicine Online 2007; 14 (Supplement 1): 130-6. www.rbmonline.com/article/2413 on web 17 November 2006.

16. Thomson JA, Itskovitz-Eldor J, Shapiro SS, Waknitz MA, Swiergiel JJ, Marshall VS, Jones JM. Embryonic stem cell lines derived from human blastocysts. Science 1998; 282: 1145-7.

17. Bongso A, Fong CY, Ng SC, Ratnam S. Isolation and culture of inner cell mass from human blastocysts. Human Reproduction 1994; 9: 2110-7.

18. Reubinoff B. Current status of human embryonic stem cell research. In: Ethics, Law and Moral Philosophy of Reproductive Biomedicine (Istanbul, Turkey 28 - 29 April 2006). Reproductive BioMedicine Online 2007; 14 (Supplement 1): 121-4. www.rbmonline.com/article/2608 on web 17 November 2006.

19. Yu LC, Wall DC, Sandler E, Chan KW, Grayson G, Keltzel M. Unrelated cord blood transplant experience by the pediatric blood and bone marrow consortium. Pediatric Hematology and Oncology 2001; 18: 235-45.

20. De Coppi P. Stem cells derived from amniotic fluid: new potentials in regenerative medicine (Contributions from the 3rd International Conference on Science and Ethics of Assisted Reproduction and Stem Cell Research, November 2007, Berlin). Reproductive BioMedicine Online 2009; 18 (Supplement 1): 17-27. www.rbmonline.com/article/3535 on web 27 January 2009.

21. Baird DT. Current concepts on the role of LH and FSH in follicular development. Ed. Ben Rafael Z, Diedrich K, Dudenhausen J-W, Mettler L, Schneider HPG, Shoham Z. Proceedings of the 4th Congress on Controversies in Obstetrics, Gynaecology and Infertility, Berlin, Germany, 24 - 27 April 2003. E Oren Publisher Ltd, Israel. 214-21.

22. Pennings G. The ethics of using embryos in research. In: Ethics, Law and Moral Philosophy of Reproductive Biomedicine (Istanbul, Turkey 28 - 29 April 2006). Reproductive BioMedicine Online 2007; 14 (Supplement 1): 92-7. www.rbmonline.com/article/2411 on web 10 July 2006.

23. Teramoto S, Kato O. Minimal ovarian stimulation with clomiphene citrate: a large scale retrospective study. Reproductive BioMedicine Online 2007; 15: 134-48. www.rbmonline.com/Article/2711 on web 13 June 2007. 
24. HFEA Code of Practice 7th edition - R.4. First Published in 2007. Presented to Parliament pursuant to section 26 of the Human Fertiliation and Embryology Act 1990. The Human Fertilization and Embryology Authority, 21 Bloomsbury Street, London WC1B 3HF, admin@hfea.gov.uk, http:// www.hfea.gov.uk

25. Sri Lanka Medical Council. A Provisional Code of Practice for Assisted Reproductive Technologies 2005.

26. Pennings G, Devroey P. Subsidized in-vitro fertilization treatment and the effect on the number of egg sharers. Reproductive BioMedicine Online 2006; 13: 8-10. www.rbmonline.com/article/2307 on web 8 May 2006.

27. Gurgan T. Unresolved issues regarding assisted reproduction technology. In: Ethics, Law and Moral Philosophy of Reproductive Biomedicine (Istanbul, Turkey 28 - 29 April 2006). Reproductive BioMedicine Online 2007; 14 (Supplement 1): 40-43. www.rbmonline.com/article/ 2495 on web 16 November 2006
28. United Nations Universal Declaration of Human Rights. General Assembly resolution 217 A (III) of 10 December 1948. http:// www.un.org/Overview/rights.html

29. Merkel R. The legal status of the human embryo. In: Ethics, Law and Moral Philosophy of Reproductive Biomedicine (Istanbul, Turkey 28-29 April 2006). Reproductive BioMedicine Online 2007; 14 (Supplement 1): 54-60. www.rbmonline. com/article/2631 on web 14 December 2006.

30. Galton D. Ethics or legislation for regulation of assisted reproduction technology? In: Ethics, Law and Moral Philosophy of Reproductive Biomedicine (Istanbul, Turkey 28 - 29 April 2006). Reproductive BioMedicine Online 2007; 14 (Supplement 1): 19-23. www.rbmonline.com/article/ 2561 on web 14 November 2006.

31. Teramoto S, Kato O. Minimal ovarian stimulation with clomiphene citrate: a large scale retrospective study. Reproductive BioMedicine Online 2007; 15: 134-48. www.rbmonline.com/Article/2711 on web 13 June 200 